\title{
Desmodesmus e Scenedesmus (Scenedesmaceae, Sphaeropleales, Chlorophyceae) em ambientes aquáticos na Planície Costeira do Rio Grande do Sul, Brasil ${ }^{1}$
}

\author{
Desmodesmus and Scenedesmus (Scendesmaceae, Sphaeropleales, Chlorophyceae) \\ in aquatic environments from the Coastal Plain of Rio Grande do Sul, Brazil
}

\author{
Guilherme Scotta Hentschke $e^{2} \&$ Lezilda Carvalho Torgan ${ }^{3}$
}

\begin{abstract}
Resumo
Este estudo trata da flora de Desmodesmus An, Friedl \& Hegew. e Scenedesmus Meyen, encontrada em lagoas isoladas, lagoas interligadas, banhados, açudes e ambientes lóticos da Planície Costeira do Rio Grande do Sul. A composição taxonômica e as relações entre a riqueza e a densidade com as variáveis temperatura e pH foram avaliadas. O estudo baseou-se em 41 amostragens efetuadas no outono (período de águas altas) e na primavera (período de águas baixas) de 2003. Treze espécies e três variedades de Desmodesmus, e duas espécies e uma variedade de Scenedesmus foram identificadas. Dentre essas espécies, quatro combinações novas (Desmodesmus granulatus (W.\& G.S. West.) Hentschke \& Torgan, D. heteracanthus (Guerr.) Hentschke \& Torgan, D. microspina (Chod.) Hentschke \& Torgan e D. spinoso-aculeolatus (Chod.) Hentschke \& Torgan) são propostas. As maiores riquezas e densidades foram observadas onde o $\mathrm{pH}$ apresentou valor mais baixo. A média de densidade (ind. $\mathrm{mL}^{-1}$ ) de Desmodesmus e Scenedesmus na primavera foi significativamente maior que a média obtida no outono, devido provavelmente aos maiores valores de temperatura da água, como também à diminuição do nível de água, o que possibilitou a maior concentração de organismos.

Palavras-chave: Chlorophyta, densidade, hidroperíodo, riqueza, taxonomia.

Abstract

This study on the Desmodesmus An, Friedl \& Hegew. and Scenedesmus Meyen flora was developed in isolated ponds, interlinked ponds, marshes, dams and lotic environments of the Rio Grande do Sul Coastal Plain. 41 samples collected in autumn and spring 2003 were analysed. 13 species and three varieties of Desmodesmus and two species and one variety of Scenedesmus were identified. Four new combinations were proposed: Desmodesmus granulatus (W. \& G.S. West.) Hentschke \& Torgan, D. heteracanthus (Guerr.) Hentschke \& Torgan, D. microspina (Chod.) Hentschke \& Torgan and D. spinosoaculeolatus (Chod.) Hentschke \& Torgan. The highest values of richness and density were observed in samples with lower $\mathrm{pH}$. The average density (ind $\mathrm{mL}^{-1}$ ) of Desmodesmus and Scenedesmus in spring was significantly higher than in autumn, probably due to higher water temperature and decreased water level, enabling a higher concentration of organisms.
\end{abstract}

Key words: Chlorophyta, density, water pulse, richness, taxonomy.

\section{Introdução}

Os gêneros Desmodesmus An, Friedl \& Hegew. e Scenedesmus Meyen são de comum ocorrência em águas continentais, especialmente, em ambientes ricos em nutrientes. São importantes componentes da comunidade fitoplanctônica, pois são muito representativos em sua composição. Muitas espécies crescem facilmente em cultivo, sendo por esse motivo usadas em estudos químicos e fisiológicos (An et al. 1999).

\footnotetext{
${ }^{1}$ Parte da dissertação de Mestrado do primeiro autor. Programa de Pós-Graduação em Botânica, Universidade Federal do Rio Grande do Sul.

${ }^{2}$ Universidade Federal do Rio Grande do Sul, Programa de Pós-graduação em Botânica, Av. Bento Gonçalves 9500, Campus do Vale, 91501-970, Porto Alegre, RS, Brasil.guilherme.scotta@gmail.com

${ }^{3}$ Fundação Zoobotânica do Rio Grande do Sul, Museu de Ciências Naturais, R. Dr. Salvador França 1427, 90690-000, Porto Alegre, RS, Brasil. lezilda.torgan@fzb.rs.gov.br.
} 
Scenedesmus foi descrito por Meyen (1829) para algas cocóides, autospóricas, com cenóbios planos ou curvos. Hegewald (1978) delimitou para esse gênero, com base na forma dos pólos das células e na presença de ornamentações, os subgêneros Scenedesmus Meyen, Acutodesmus Hegew. e Desmodesmus Chod. Recentemente An et al. (1999) e Tsarenko \& Petlevanny (2001) elevaram Desmodesmus e Acutodesmus à categoria de gênero, em estudos utilizando biologia molecular. O gênero Desmodesmus mostrou-se monofilético e diferencia-se de Scenedesmus por apresentar uma quarta camada de esporolenina na parede celular, o que possibilita a formação dos espinhos e das demais ornamentações (An et al. 1999; Hegewald 2000). Acutodesmus diferencia-se de Scenedesmus por apresentar células com pólos agudos. Entretanto ainda não é confirmado como gênero independente, pelo fato de ser parafilético (Hegewald \& Wolf 2003). Atualmente, Desmodesmus e Scenedesmus estão incluídos na classe Chlorophyceae, ordem Sphaeropleales, família Scenedesmaceae (Lewis \& McCourt 2004).

A plasticidade morfológica em Scenedesmus s.l. levou os ficólogos a descreverem 1.300 táxons específicos e infra-específicos (Hegewald \& Silva 1988; Hegewald \& Wolf 2003). A partir da década de oitenta, muitos trabalhos foram publicados, dentre eles mencionam-se Hegewald (1989) e Hegewald et al. (2001), tratando das variações morfológicas apresentadas por esse gênero. Porém, a taxonomia do grupo ainda permanece incerta.

No estado do Rio Grande do Sul, Desmodesmus e Scenedesmus são comumente citados em investigações sobre fitoplâncton (Torgan et al. 2001). Estudos detalhados, com descrições e ilustrações dos táxons, são escassos. Dentre os existentes podem-se destacar os trabalhos de Rosa \& Oliveira (1990), Garcia \& Vélez (1995) e o de Fortes et al. (2003).

Na Planície Costeira do Rio Grande do Sul, especificamente nas áreas da Lagoa do Casamento e Butiazal de Tapes, poucas espécies (sete de Desmodesmus e três de Scenedesmus) são listadas por Torgan et al. (2007). O presente estudo visa ampliar o conhecimento taxonômico destes gêneros e avaliar suas riquezas e densidades, em relação aos ambientes e aos períodos de amostragem.

\section{Material e Métodos}

As amostragens foram efetuadas nas estações de outono (maio/2003) e primavera (outubro/2003), períodos que (na ocasião das coletas) foram de águas altas e baixas, respectivamente. Coletou-se em diferentes ambientes das áreas do Butiazal de Tapes e da Lagoa do Casamento (Tab. 1), localizadas na Planície Costeira do Rio Grande do Sul, entre as coordenadas $30^{\circ} 40^{\prime}-30^{\circ} 10^{\prime} \mathrm{S}$ e $50^{\circ} 30^{\prime}-51^{\circ} 31^{\prime} \mathrm{W}$ (Fig. 1).

As amostras foram obtidas através da passagem de frascos e rede de plâncton $(25 \mu \mathrm{m})$ na subsuperfície da água, nas zonas pelágicas e litorâneas e fixadas com formaldeído, nas proporções 1:100 e 4:100, respectivamente (Bicudo \& Menezes 2005). As amostras obtidas encontram-se tombadas no Herbário Prof. Dr. Alarich Shultz (HAS), no Museu de Ciências Naturais do Rio Grande do Sul. Concomitante às coletas de microalgas, efetuaram-

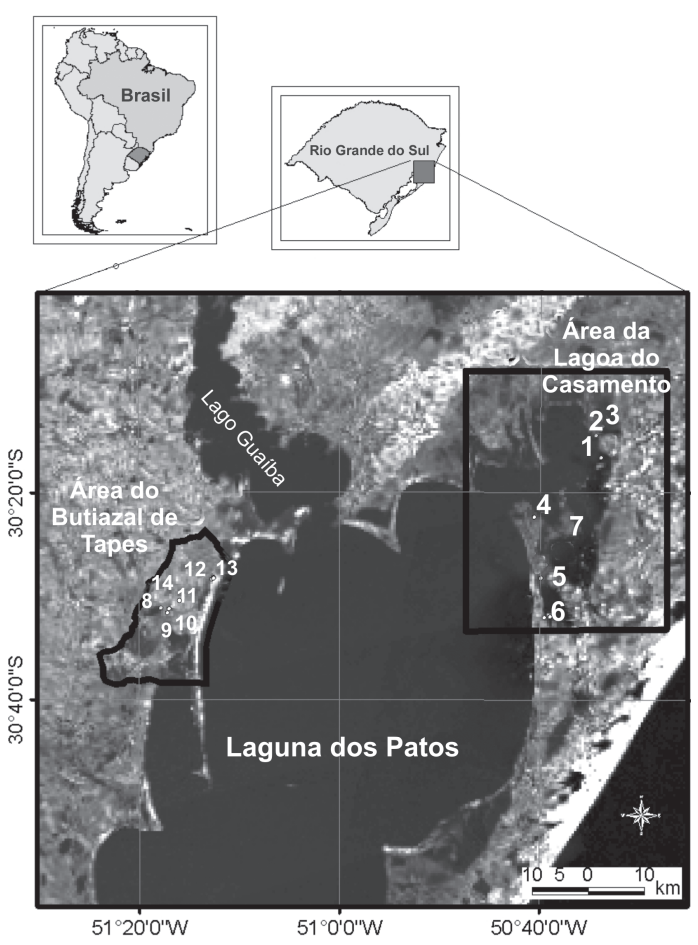

Figura 1 - Localização dos ambientes amostrados nas áreas da Lagoa do Casamento e do Butiazal de Tapes, na Planície Costeira do Rio Grande do Sul. 1. Lagoa do Casamento; 2. Banhado entre Lagoa Capivari e Lagoa do Casamento; 3. Lagoa Capivari; 4. Banhado Fazenda Rincão do Anastácio; 5. Canal do Sangradouro; 6. Lagoa dos Gateados; 7. Banhado Ilha Grande; 8. Lagoa das Capivaras; 9. Lagoa Redonda; 10. Lagoa do Charutão; 11. Banhado com Sphagnum; 12. Açude Fazenda São Miguel; 13. Lagoa entre Dunas e Banhado entre Dunas; 14. Arroio Araçá.

Figure 1 - Sampled environments in Lagoa do Casamento and Butiazal de Tapes areas, in Coastal Plain of Rio Grande do Sul. 
Tabela 1 - Relação do material examinado e dos métodos de coleta ( $F=$ frasco; $R=$ rede), no outono e primavera de 2003. Table 1 - List of the examined material with types of sampling ( $\mathrm{F}=$ flask; $\mathrm{R}=$ plankton net), in autumn and spring 2003.

\begin{tabular}{|c|c|c|c|c|c|}
\hline Município & Ambientes & Data de Coleta & Coletor & Método & HAS \\
\hline Capivari do Sul & B. L. Capivari e L. Casamento & $5 / 5 / 2003$ & V. Werner & $\mathrm{F}$ & 104097 \\
\hline Palmares do Sul & L. do Casamento & $5 / 5 / 2003$ & V. Werner & $\mathrm{F}$ & 104104 \\
\hline Palmares do Sul & L. do Casamento & $5 / 5 / 2003$ & L. Torgan & $\mathrm{F}$ & 104111 \\
\hline Palmares do Sul & B. Faz. Rincão do Anastácio & $7 / 5 / 2003$ & V. Werner & $\mathrm{F}$ & 104119 \\
\hline Palmares do Sul & B. Faz. Rincão do Anastácio & $7 / 5 / 2003$ & V. Werner & $\mathrm{F}$ & 104120 \\
\hline Palmares do Sul & B. Faz. Rincão do Anastácio & $7 / 5 / 2003$ & V. Werner & $\mathrm{R}$ & 104122 \\
\hline Palmares do Sul & B. Faz. Rincão do Anastácio & $7 / 5 / 2003$ & V. Werner & $\mathrm{F}$ & 104123 \\
\hline Mostardas & L. dos Gateados & $7 / 5 / 2003$ & V. Werner & $\mathrm{F}$ & 104132 \\
\hline Mostardas & C. Sangradouro & $7 / 5 / 2003$ & L. Torgan & $\mathrm{F}$ & 104169 \\
\hline Mostardas & L. dos Gateados & $9 / 5 / 2003$ & V. Werner & $\mathrm{F}$ & 104177 \\
\hline Mostardas & L. dos Gateados & $9 / 5 / 2003$ & L. Torgan & $\mathrm{F}$ & 104184 \\
\hline Tapes & L. do Charutão & $3 / 6 / 2003$ & V.Werner & $\mathrm{F}$ & 104196 \\
\hline Tapes & B. com Sphagnum & $4 / 6 / 2003$ & L. Torgan \& V. Werner & $\mathrm{R}$ & 104220 \\
\hline Tapes & B. com Sphagnum & $4 / 6 / 2003$ & L. Torgan \& V. Werner & $\mathrm{F}$ & 104221 \\
\hline Tapes & L. entre Dunas & $4 / 6 / 2003$ & L. Torgan & $\mathrm{F}$ & 104229 \\
\hline Tapes & B. entre Dunas & $4 / 6 / 2003$ & L. Cardoso & $\mathrm{R}$ & 104231 \\
\hline Tapes & B. entre Dunas & $4 / 6 / 2003$ & L. Cardoso & $\mathrm{F}$ & 104233 \\
\hline Tapes & L. Redonda & $4 / 6 / 2003$ & L. Torgan \& V. Werner & $\mathrm{R}$ & 104235 \\
\hline Tapes & L. Redonda & $4 / 6 / 2003$ & L. Torgan \& V. Werner & $\mathrm{F}$ & 104238 \\
\hline Capivari do Sul & B. L. Capivari e L. Casamento & $27 / 10 / 2003$ & S. Alves-da-Silva & $\mathrm{R}$ & 104337 \\
\hline Capivari do Sul & B. L. Capivari e L. Casamento & $27 / 10 / 2003$ & S. Alves-da-Silva & $\mathrm{F}$ & 104341 \\
\hline Palmares do Sul & L. do Casamento & $27 / 10 / 2003$ & S. Alves-da-Silva & $\mathrm{F}$ & 104349 \\
\hline Palmares do Sul & L. do Casamento & $18 / 11 / 2003$ & L. Cardoso & $\mathrm{R}$ & 104352 \\
\hline Palmares do Sul & L. do Casamento & $18 / 11 / 2003$ & L. Cardoso & $\mathrm{F}$ & 104354 \\
\hline Palmares do Sul & L. do Casamento & $19 / 11 / 2003$ & L. Cardoso & $\mathrm{R}$ & 104356 \\
\hline Palmares do Sul & L. do Casamento & $19 / 11 / 2003$ & L. Cardoso & $\mathrm{F}$ & 104358 \\
\hline Palmares do Sul & B. Faz. Rincão do Anastácio & $29 / 10 / 2003$ & S. Alves-da-Silva & $\mathrm{R}$ & 104362 \\
\hline Palmares do Sul & B. Faz. Rincão do Anastácio, & $29 / 10 / 2003$ & S. Alves-da-Silva & $\mathrm{F}$ & 104363 \\
\hline Palmares do Sul & C. Sangradouro & $19 / 11 / 2003$ & L. Cardoso & $\mathrm{F}$ & 104384 \\
\hline Palmares do Sul & B. Ilha Grande & $29 / 11 / 2003$ & S. Alves-da-Silva & $\mathrm{F}$ & 104395 \\
\hline Palmares do Sul & L. Ilha Grande & $29 / 10 / 2003$ & S. Alves-da-Silva & $\mathrm{R}$ & 104396 \\
\hline Tapes & A. Faz. São Miguel & $2 / 12 / 2003$ & L. Cardoso & $\mathrm{R}$ & 104427 \\
\hline Tapes & A. Faz. São Miguel & $2 / 12 / 2003$ & L. Cardoso & $\mathrm{F}$ & 104429 \\
\hline Tapes & B. com Sphagnum & $3 / 12 / 2003$ & L. Cardoso & $\mathrm{F}$ & 104440 \\
\hline Tapes & L. entre Dunas & $3 / 12 / 2003$ & L. Cardoso & $\mathrm{R}$ & 104442 \\
\hline Tapes & L. entre Dunas & $3 / 12 / 2003$ & L. Cardoso & $\mathrm{F}$ & 104443 \\
\hline Tapes & B. entre Dunas & $3 / 12 / 2003$ & L. Cardoso & $\mathrm{R}$ & 104446 \\
\hline Tapes & B. entre Dunas & $3 / 12 / 2003$ & L. Cardoso & $\mathrm{F}$ & 104447 \\
\hline Tapes & L. Redonda & $3 / 12 / 2003$ & L. Cardoso & $\mathrm{R}$ & 104450 \\
\hline Tapes & L. Redonda & $2 / 12 / 2003$ & L. Cardoso & $\mathrm{F}$ & 104453 \\
\hline Tapes & A. Araçá & $3 / 12 / 2003$ & L. Cardoso & $\mathrm{F}$ & 104457 \\
\hline
\end{tabular}


se medidas de temperatura e de $\mathrm{pH}$ através de aparelhos eletrônicos marca HACH, modelos 50150 e 50050 .

Para a análise taxonômica dos organismos utilizou-se microscópio óptico Zeiss Axioplan, equipado com contraste de fase. Os organismos foram registrados através de desenhos, fotomicrografias utilizando-se câmera Zeiss MC63 e microscópio eletrônico de varredura (MEV), marca JEOL JSM-6060, operado em 10 kV. Para a análise em MEV, o material foi colocado em lâminas de raios$\mathrm{X}$ sobre suporte apropriado e metalizado com platina, sem preparação em ponto-crítico.

A identificação das espécies foi processada, principalmente, com base nas obras clássicas de Komàrek \& Fott (1983), Hegewald \& Silva (1988), Hindàk (1990) e Hegewald (2000); o tipo de disposição dos espinhos e de ornamentações, mencionados nas descrições das espécies (Fig. 2), foram adaptados de Komàrek \& Fott (1983). As referências de primeiras citações para o estado do Rio Grande do Sul foram baseadas no catálogo de Chlorophyta de Torgan et al. (2001) e nos estudos de Fortes et al. (2003) e Torgan et al. (2007).

A densidade dos organismos foi estimada através da quantificação em amostras coletadas com passagem de frasco, em câmaras de sedimentação, ao microscópio invertido, segundo o método Utermöhl (1958), procurando-se atingir uma eficiência amostral de 80\% (Pappas \& Stoermer 1996). Para a análise estatística dos dados, foi utilizado como ferramenta computacional o programa SigmaPlot 11.0. Visando à busca de relação entre as variáveis densidade e riqueza versus $\mathrm{pH}$ e temperatura, foi utilizado o teste de correlação não-paramétrica de Spearman. Para a comparação das médias das variáveis riqueza (distribuição normal) e densidade (sem distribuição normal), entre estações (outono e primavera) e localizações (zonas litorânea e pelágica), foram utilizados os testes $t$ de Student e MannWhitney, respectivamente. Em todas as análises foi considerada a significância de $\mathrm{p}<0,05$.

\section{Resultados e Discussão}

O resultado da análise de 41 amostras revelou a presença de 13 espécies e três variedades, sendo duas que não as típicas de Desmodesmus e, duas espécies e uma variedade, que não a típica de Scenedesmus. Dentre essas espécies, quatro combinações novas são propostas. Apresentamos a seguir as descrições e medidas dos táxons identificados.

\section{Composição taxonômica}

Desmodesmus armatus (Chod.) Hegew. var. armatus, Algol. Stud. 96: 2. 2000.

Fig. 3a-b, 4a-b

Cenóbios planos, com duas ou quatro células dispostas linearmente. Células internas elipsóides, as externas de elipsóides a arcuadas. Células frequentemente com costelas frontais e, às vezes, com verrugas. Espinhos principais em disposição linear. Cloroplasto único, parietal, um pirenóide. Comprimento das células 10-27 $\mu \mathrm{m}$, largura 4-9 $\mu \mathrm{m}$, comprimento dos espinhos 9-25 $\mu \mathrm{m}$.

Material examinado: HAS 104119, 104132, 104220, 104231, 104233, 104429, 104440, 104442, 104443, 104447.

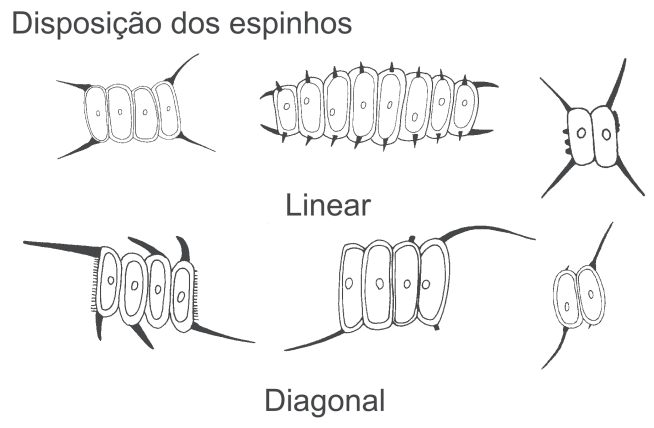

Tipos de ornamentações

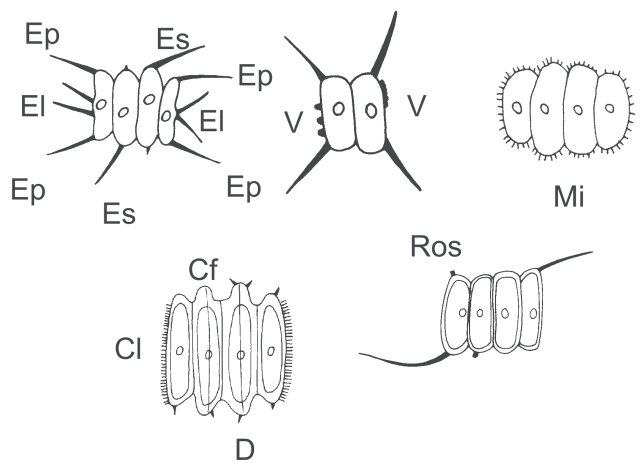

Figura 2-Disposição de espinhos e tipos de ornamentações. $\mathrm{Ep}=$ espinhos principais; $\mathrm{El}=$ espinhos laterais; $\mathrm{Es}=$ espinhos secundários; $\mathrm{V}=$ verrugas; $\mathrm{Mi}=$ microtúbulos; $\mathrm{Cf}=$ costelas frontais; $\mathrm{Cl}=$ costelas laterais; $\mathrm{D}=$ dentes; $\mathrm{Ros}=$ rosetas. (Adaptado de Komàrek \& Fott 1983)

Figure 2 - Arrangement of spines and ornamentations. Ep = main spines; $\mathrm{El}=$ lateral spines; $\mathrm{Es}=$ secundary spines; $\mathrm{V}=$ warts; $\mathrm{Mi}=$ microtubules; $\mathrm{Cf}=$ frontal ribs; $\mathrm{Cl}=$ lateral ribs; $\mathrm{D}=$ teeth; $\mathrm{Ros}=$ rosettes. (Adaptation of Komàrek \& Fott 1983) 
Desmodesmus armatus var. bicaudatus (Gugl.) Hegew., Algol. Stud. 96: 4. $2000 . \quad$ Fig. 3c-g, 4c-f

Cenóbios planos, com duas ou quatro células dispostas linearmente. Células internas de elipsóides a oblongas, as externas elipsóides, oblongas ou arcuadas. Rosetas, costelas frontais, dentes ou microtúbulos frequentemente presentes. Espinhos principais em disposição diagonal, às vezes, espessados nas bases. Cloroplasto único, parietal, um pirenóide. Comprimento das células $7-$ $26 \mu \mathrm{m}$, largura 3-10 $\mu \mathrm{m}$, comprimento dos espinhos $7-25 \mu \mathrm{m}$.

Material examinado: HAS 104097, 104132, 104184, 104220, 104221, 104229, 104233, 104238,104346, $104349,104363,104396,104429,104443,104446$, 104447, 104450, 104453.

Desmodesmus brasiliensis (Bohl.) Hegew., Algol. Stud. 96: 7. 2000.

Fig. 3h-1, 4g-i, 5a-d

Cenóbios planos, com quatro células dispostas linearmente. Células oblongas. Presença de costelas frontais bem marcadas e, frequentemente, de um a três dentes nos pólos das células. Costelas laterais, às vezes presentes. Cloroplasto único, parietal, um pirenóide. Comprimento das células 10-25 $\mu \mathrm{m}$, largura 4-8 $\mu \mathrm{m}$. Material examinado: HAS 104119, 104122, 104123, 104196, 104220, 104221, 104341, 104362, 104429, 104440, 104442, 104443, 104446, $104450,104457$.

Desmodesmus communis (Hegew.) Hegew., Algol. Stud. 96: 8. 2000.

Fig. $3 m, 4 j$

Scenedesmus pseudoquadricauda Hortob., Acta Bot. Acad. Sci. Hung. 17: 84, 89, fig. 1. 1972.

Cenóbios planos, com quatro células dispostas linearmente. Células oblongas. Espinhos em disposição linear, com base espessada. Cloroplasto único, parietal, um pirenóide. Comprimento das células 8,5-12 $\mu \mathrm{m}$, largura 3,75$7 \mu \mathrm{m}$, comprimento dos espinhos 5-9 $\mu \mathrm{m}$.

Scenedesmus pseudoquadricauda Hortob. foi descrita como uma nova espécie, separada de S. quadricauda (Turp.) Bréb., por apresentar espinhos com base espessada. Esta foi combinada em D. communis por Hegewald (2000) e $S$. pseudoquadricauda não foi incluída na lista de sinônimos. De acordo com as combinações propostas por Hegewald (2000), a base espessada dos espinhos parece não ser uma boa característica para separar espécies (ver $D$. armatus var. bicaudatus), motivo pelo qual considera-se S. pseudoquadricauda sinônimo de D. communis.
Material examinado: HAS 104104, HAS 104111, HAS 104184.

Desmodesmus costato-granulatus (Skuja) Hegew. var. elegans (Hortob.) Hegew., Algol. Stud. 96: 9. 2000.

Fig. 3n-p, 4k-1, 5e, 6a

Cenóbios planos, com duas células dispostas linearmente. Células elipsóides, com microtúbulos na parede celular. Cloroplasto único, parietal, um pirenóide. Comprimento das células 9-11 $\mu \mathrm{m}$, largura 3-4 $\mu \mathrm{m}$.

A espécie pode apresentar cenóbios de duas a quatro células com forma e ornamentação muito variável. As costelas costumam ser pouco nítidas, sendo observadas somente em células sem conteúdo (Hegewald \& Krienitz 1993). Esta é a primeira citação da espécie para o estado do Rio Grande do Sul.

Material examinado: HAS 104442.

Desmodesmus granulatus (W.\& G.S. West.)Hentschke \& Torgan comb. nov. Scenedesmus granulatus $\mathrm{W}$. \& G.S. West. J. Roy. Micr. Soc. 1897: 500, pl. VII, figs. 1,2. 1897.

Fig. 3q, 6b

Scenedesmus granulatus $f$. bigranulatus Hortob. Nov. Hedwig. 1: 346, fig. 86. 1960.

Cenóbios planos, com quatro células dispostas linearmente. Células oblongas, com verrugas nas faces laterais. Cloroplasto único, parietal, um pirenóide. Comprimento das células $7-11 \mu \mathrm{m}$, largura $2-3 \mu \mathrm{m}$.

A presença de ornamentações na parede celular permite a transferência da espécie para gênero Desmodesmus (An et al. 1999). Esta é a primeira citação da espécie para o estado do Rio Grande do Sul.

Material examinado: HAS 104119, 104429, 104440, $104442,104443$.

Desmodesmus heteracanthus (Guerr.) Hentschke \& Torgan comb. nov. Fig. 3r, 6c Scenedesmus heteracanthus Guerr., An. Jard. Bot. Madrid 1:154, fig I: 8. 1941.

Cenóbios planos, com quatro células em disposição levemente alternada. Células internas elipsóides, com um espinho secundário curto em um dos pólos; externas arcuadas, com um espinho principal longo e um curto, dispostos em posição perpendicular. Espinhos principais em disposição diagonal. Cloroplasto único, parietal, um pirenóide. Comprimento das células 10-13 $\mu \mathrm{m}$, largura 3-4 $\mu \mathrm{m}$. Comprimento dos espinhos longos 10-14 $\mu \mathrm{m}$, espinhos curtos 3-5 $\mu \mathrm{m}$. 

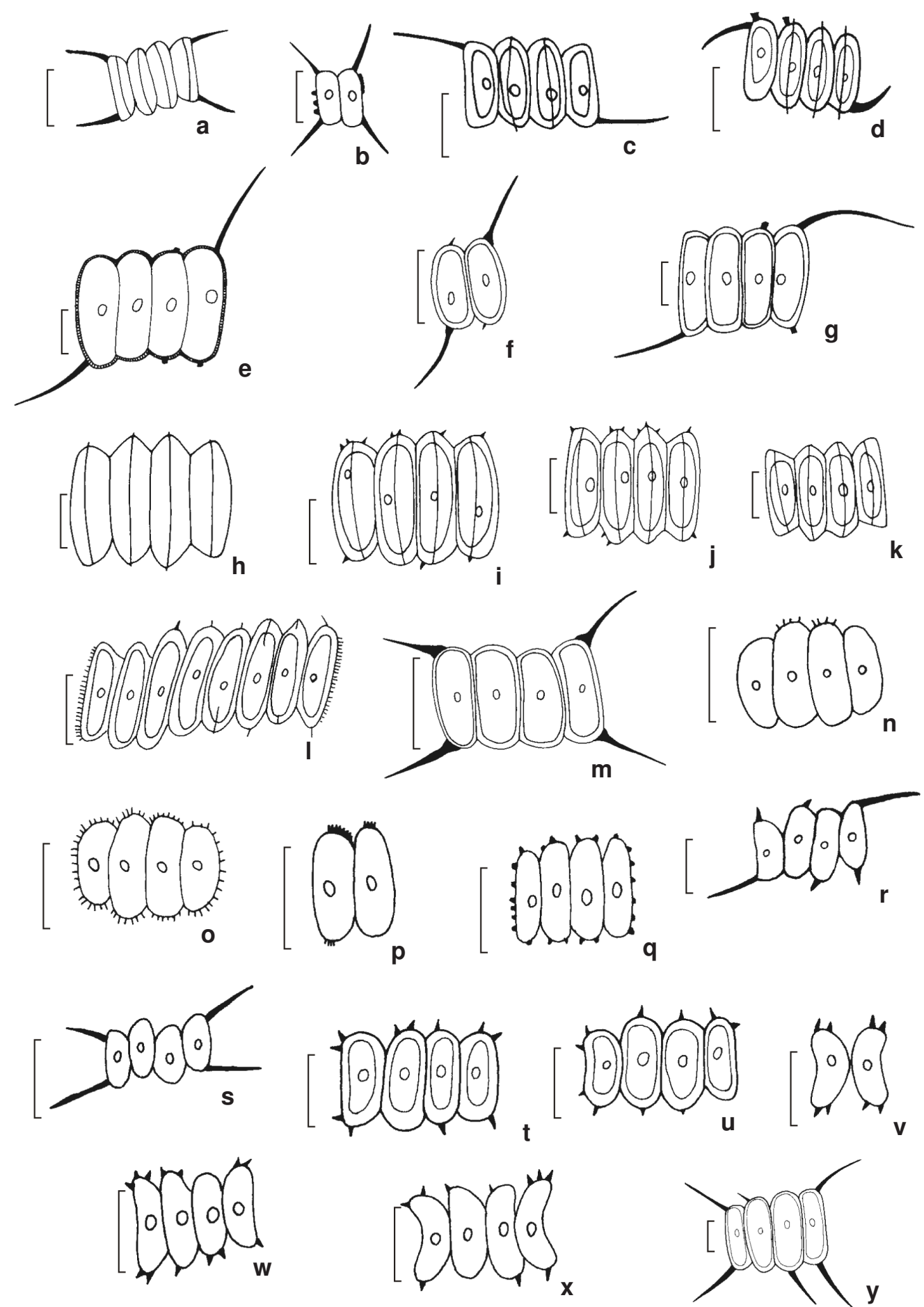

Figura 3 -a-b. Desmodesmus armatus var. armatus. c-g. D. armatus var. bicaudatus. h-1. D. brasiliensis. m. D. communis. n-p. D. costato-granulatus var. elegans. q. D. granulatus. r. D. heteracanthus. s. D. intermedius. t-u. D. komarekii. v-x. D. lunatus; y. D. maximus. Barras $=10 \mu \mathrm{m}$.

Figure 3 - a-b. Desmodesmus armatus var. armatus. c-g. D. armatus var. bicaudatus. h-1. D. brasiliensis. m. D. communis. n-p. D. costatogranulatus var. elegans. q. D. granulatus. r. D. heteracanthus. s. D. intermedius. t-u. D. komarekii. v-x. D. lunatus. y. D. maximus. Bars $=10 \mu \mathrm{m}$. 

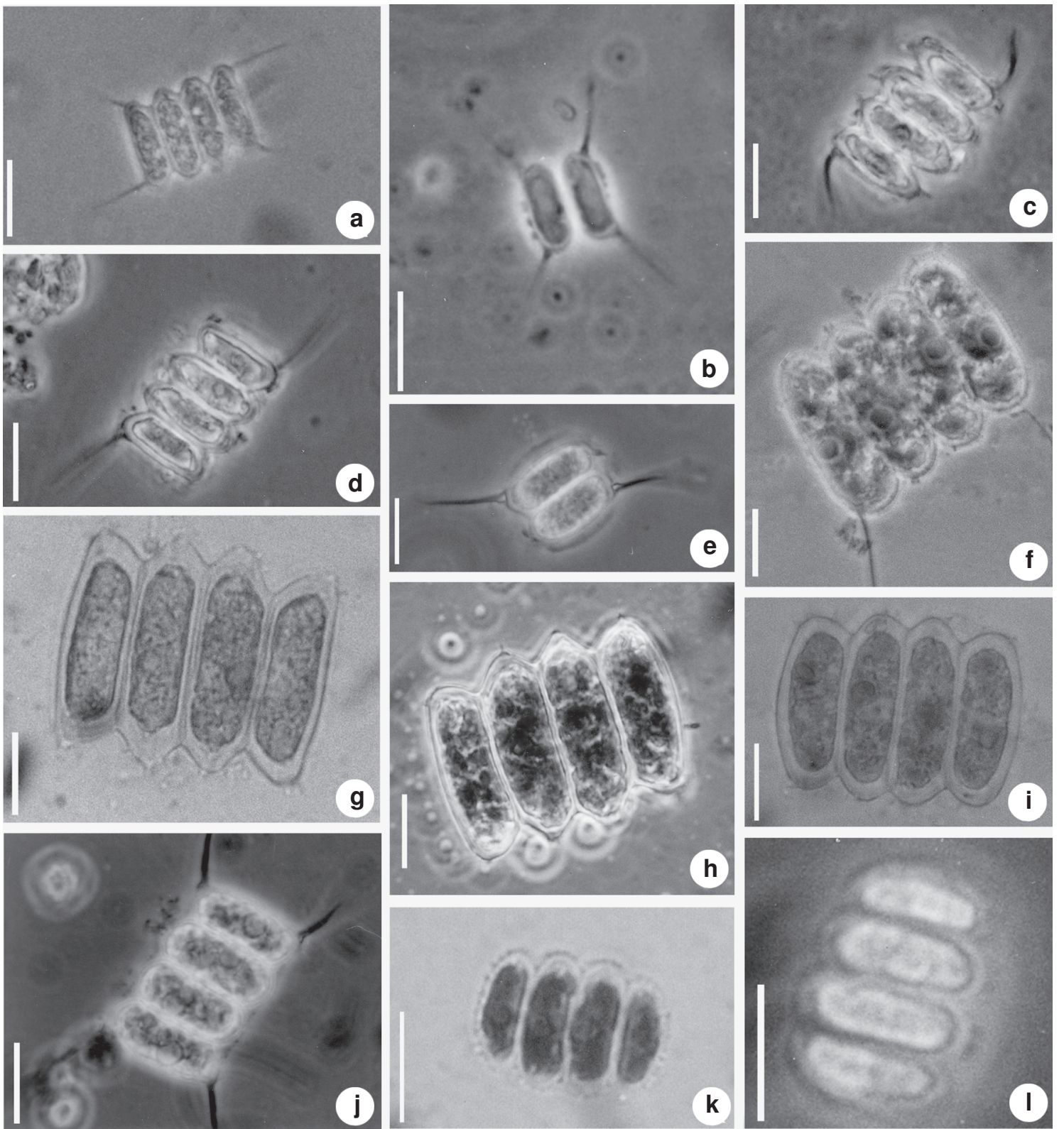

h

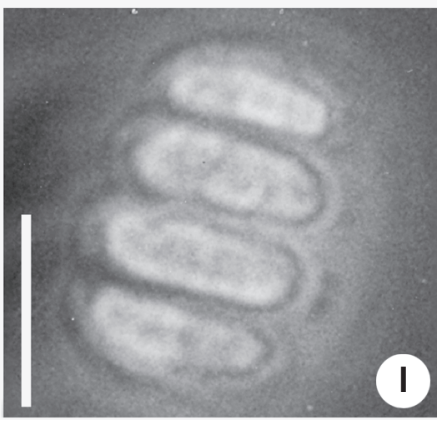

Figura 4 - a-b. Desmodesmus armatus var. armatus. c-f. D. armatus var. bicaudatus. g-i. D. brasiliensis. j. D. communis . $\mathrm{k}-1$. D. costato-granulatus var. elegans. Barras $=10 \mu \mathrm{m}$.

Figure 4 - a-b. Desmodesmus armatus var. armatus. c-f. D. armatus var. bicaudatus. g-i. D. brasiliensis. j. D. communis. k-1. D. costatogranulatus var. elegans. Bars $=10 \mu \mathrm{m}$.

Os exemplares diferem do tipo (Hegewald \& Silva 1988 p. 262, fig. 421) por apresentarem células em disposição levemente alternada. A presença de ornamentações na parede celular permite a transferência da espécie para o gênero Desmodesmus (An et al. 1999). Esta é a primeira citação da espécie para o estado do Rio Grande do Sul.

Material examinado: HAS 104446.
Desmodesmus intermedius (Chod.) Hegew., Algol. Stud. 96: 11. 2000.

Fig. 3s, 6d

Cenóbios planos, com quatro células dispostas alternadamente. Células elipsóides. Espinhos principais em disposição linear. Cloroplasto único, parietal, um pirenóide. Comprimento das células 4,5-19 $\mu \mathrm{m}$, largura $2-8,5 \mu \mathrm{m}$, comprimento dos espinhos $4-17 \mu \mathrm{m}$.

Material examinado: HAS 104104, 104114, 104169, 104337. 

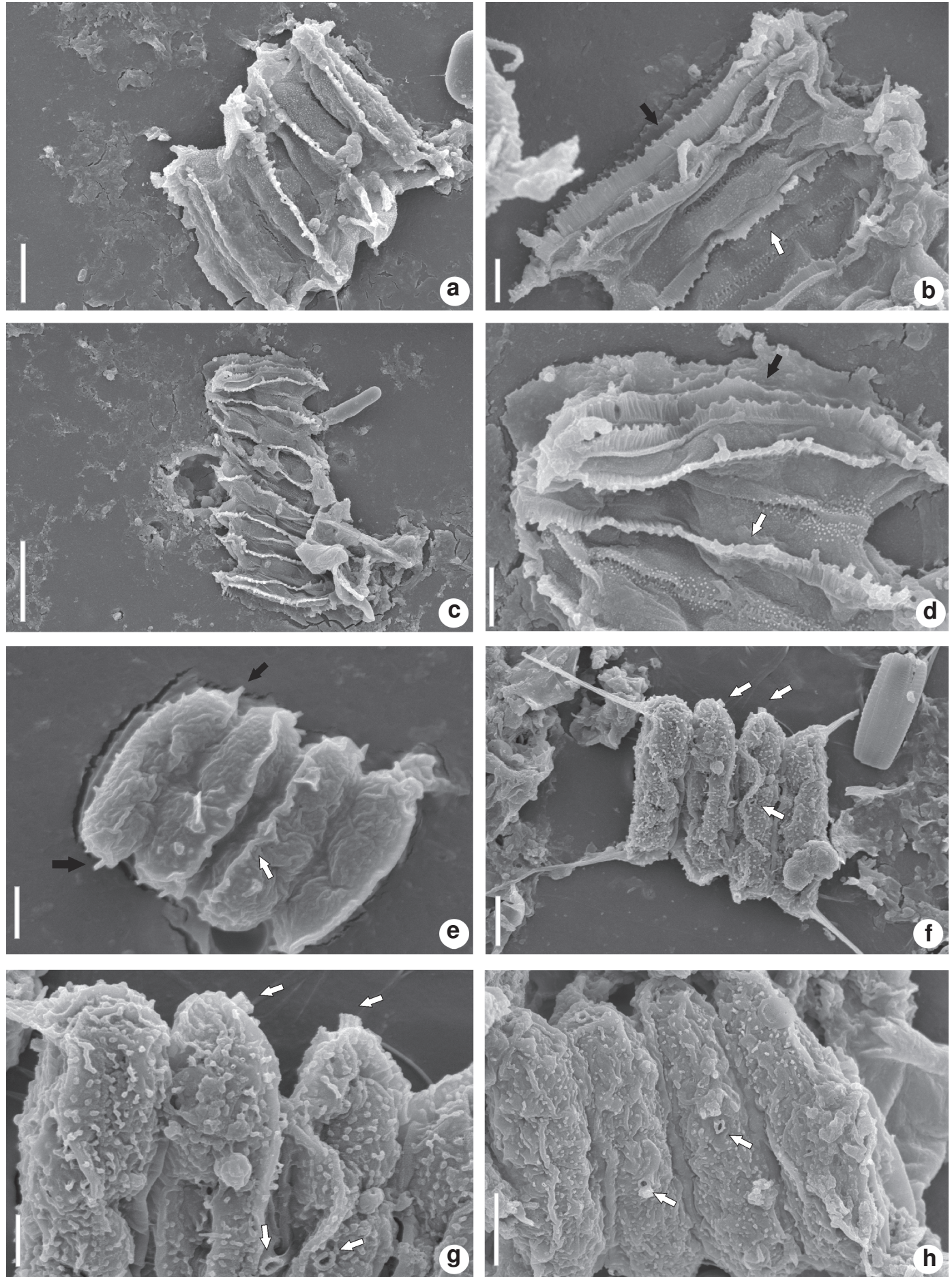

Figura 5 - a-d. Desmodesmus brasiliensis apresentando costelas frontais (setas brancas) e laterais (setas pretas). e. Vista geral de D. costato-granulatus var. elegans com costelas frontais (seta branca) e microtúbulos (setas pretas). f-h. Vista geral e detalhes da parede celular de D. maximus com rosetas (setas brancas). Barras $=2 \mu \mathrm{m}(\mathrm{b}, \mathrm{d}, \mathrm{e}, \mathrm{g}) ; 5 \mu \mathrm{m}$ (a, f, h); $10 \mu \mathrm{m}$ (c).

Figure 5 - a-d. Desmodesmus brasiliensis showing frontal ribs (white arrows) and lateral ribs (black arrows). e. General view of D. costato-granulatus var. elegans with frontal ribs (white arrow) and microtubules (black arrows). f-h. General view and cell wall details of $D$. maximus with rosettes (white arrows). Bars $=2 \mu \mathrm{m}(\mathrm{b}, \mathrm{d}, \mathrm{e}, \mathrm{g}) ; 5 \mu \mathrm{m}(\mathrm{a}, \mathrm{f}, \mathrm{h}) ; 10 \mu \mathrm{m}$ (c). 
Desmodesmus komarekii (Hegew.) Hegew., Algol. Stud. 96: 12. 2000.

Fig. 3t-u, 6e

Cenóbios planos, com quatro células dispostas linearmente. Células internas elipsóides e externas arcuadas ou levemente reniformes. Presença freqüente de um a dois dentes em cada pólo das células. Cloroplasto único, parietal, um pirenóide. Comprimento das células 9-11,5 $\mu \mathrm{m}$, largura 3,5-4,5 $\mu \mathrm{m}$.

Esta é a primeira citação da espécie para o estado do Rio Grande do Sul.

Material examinado: HAS 104440, 104442, 104446.

Desmodesmus lunatus (W. \& G. S. West) Hegew., Algol. Stud. 96: 13. 2000.

Fig. 3v-x, $6 f$

Cenóbios planos, com quatro células dispostas linearmente, internas elipsóides e externas reniformes. Presença frequente de um a três dentes em cada pólo das células. Cloroplasto único, parietal, um pirenóide. Comprimento das células 4-9,5 $\mu \mathrm{m}$, largura 2-4 $\mu \mathrm{m}$. Material examinado: HAS 104097, 104104, 104111, 104119, 104122, 104343, 104349, 104356, 104358, 104363, 104395, 104427, 104446.

Desmodemus maximus (W. \& G. S. West) Hegew., Algol. Stud. 96: 13. 2000.

Fig. 3y, 5f-h, 6g-l, 7a-f, 8a-e

Cenóbios planos, com quatro ou oito células dispostas linearmente. Células internas de elipsóides a oblongas, externas de elipsóides a arcuadas. Espinhos secundários, rosetas, verrugas, microtúbulos e ornamentações reticuladas frequentemente presentes. Espinhos principais em posição linear. Cloroplasto único, parietal, um pirenóide. Comprimento das células 16-28 $\mu \mathrm{m}$, largura 5-9 $\mu \mathrm{m}$, comprimento dos espinhos $10-25 \mu \mathrm{m}$.

As verrugas e as ornamentações reticuladas presentes em alguns indivíduos só puderam ser observadas em MEV.

Material examinado: HAS 104220, 104221, 104231, $104235,104238,104341,104343,104346,104349,104352$, 104354, 104356, 104358, 104362, 104381, 104384, 104395, 104396, 104416, 104427, 1044429, 104440, 104442, 104443,104446, 104447, 104450, 104453, 104457.

Desmodesmus microspina (Chod.) Hentschke \& Torgan comb. nov.

Fig. 7g-h, 8f-g, 9a

Scenedesmus microspina R. Chod., Z. Hydrol. 3:232, fig. 137. 1926.

Scenedesmus quadricauda var. microspina (Chod.) Philipose.

Cenóbios planos, com quatro células dispostas linearmente. Células elipsóides, às vezes com rosetas, microtúbulos ou costelas. Espinhos em disposição linear, um pouco mais curtos que o diâmetro celular. Cloroplasto único, parietal, um pirenóide. Comprimento das células 17-19 $\mu \mathrm{m}$, largura 8-10 $\mu \mathrm{m}$, comprimento dos espinhos 5-7 $\mu \mathrm{m}$.

De acordo com Komàrek \& Fott (1983) os espinhos de S. microspina apresentam comprimento igual ou menor do que a metade da largura da célula. No presente estudo, os cenóbios apresentaram espinhos um pouco maiores, enquanto a forma das células se manteve constante.

A espécie foi transferida para gênero Desmodesmus por apresentar ornamentações na parede celular, como previsto por An et al. (1999). Material examinado: HAS 104220, 104440, 104446.

Desmodesmus perforatus (Lemm.) Hegew., Algol. Stud. 96: 15. 2000. Fig. 7i-j, 9b

Cenóbios planos, com quatro células dispostas linearmente. Células internas bicôncavas, externas com face interna côncava e externa convexa. Presença de microtúbulos e, às vezes, de costelas frontais. Espinhos principais em disposição linear. Cloroplasto único, parietal, um pirenóide. Comprimento das células 15,5-18 $\mu \mathrm{m}$, largura 5-6 $\mu \mathrm{m}$, comprimento dos espinhos 9-11 $\mu \mathrm{m}$.

Material examinado: HAS 104358, 104442, 104447.

Desmodesmus serratus (Corda) An, Friedl \& Hegew. Algol. Stud. 96: 17.2000. Fig. 7k-m, 9c-e

Cenóbios planos, com quatro ou oito células dispostas linearmente. Células oblongas. Presença frequente de um a três dentes nos pólos das células. Células externas com fileira de dentes nas faces laterais. Cenóbios sem espinhos principais. Cloroplasto único, parietal, um pirenóide. Comprimento das células 12$22 \mu \mathrm{m}$, largura 3-6 $\mu \mathrm{m}$.

Esta é a primeira citação da espécie para o estado do Rio Grande do Sul.

Material examinado: HAS 104119, 104122.

Desmodesmus spinoso-aculeolatus (Chod.) Hentschke \& Torgan comb. nov. Fig. 7n-q, 9f-g Scenedesmus spinoso-aculeolatus R. Chod., Z. Hydrol. 3:235, fig. 140. 1926.

Cenóbios planos, com quatro ou oito células dispostas linearmente. Células internas elipsóides, externas arcuadas a elipsóides. Presença de um dente em cada pólo das células e, às vezes, de microtúbulos na parede celular. Espinhos principais em disposição linear. Cloroplasto único, parietal, um pirenóide. Comprimento das células 11-17 $\mu \mathrm{m}$, largura 3-6 $\mu \mathrm{m}$, comprimento dos espinhos 4-6 $\mu \mathrm{m}$. 

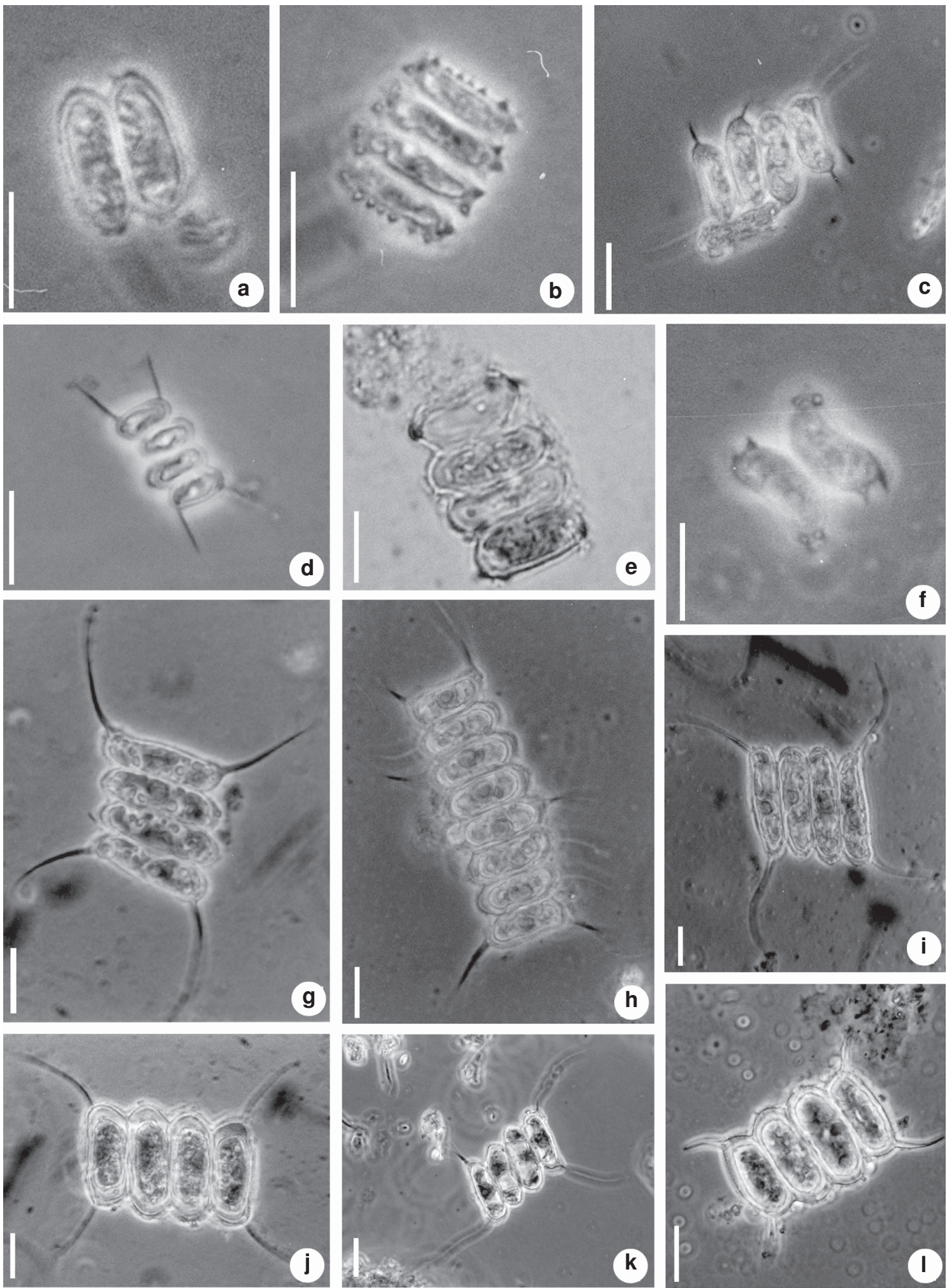

Figura 6 - a. Desmodesmus costato-granulatus var. elegans. b. D. granulatus. c. D. heteracanthus. d. D. intermedius. e. D. komarekii. f. D. lunatus. g-1. D. maximus. Barras $=10 \mu \mathrm{m}$.

Figure 6 - a. Desmodesmus costato-granulatus var. elegans. b. D. granulatus. c. D. heteracanthus. d. D. intermedius. e. D. komarekii. f. D. lunatus. g-1. D. maximus. Bars $=10 \mu \mathrm{m}$. 

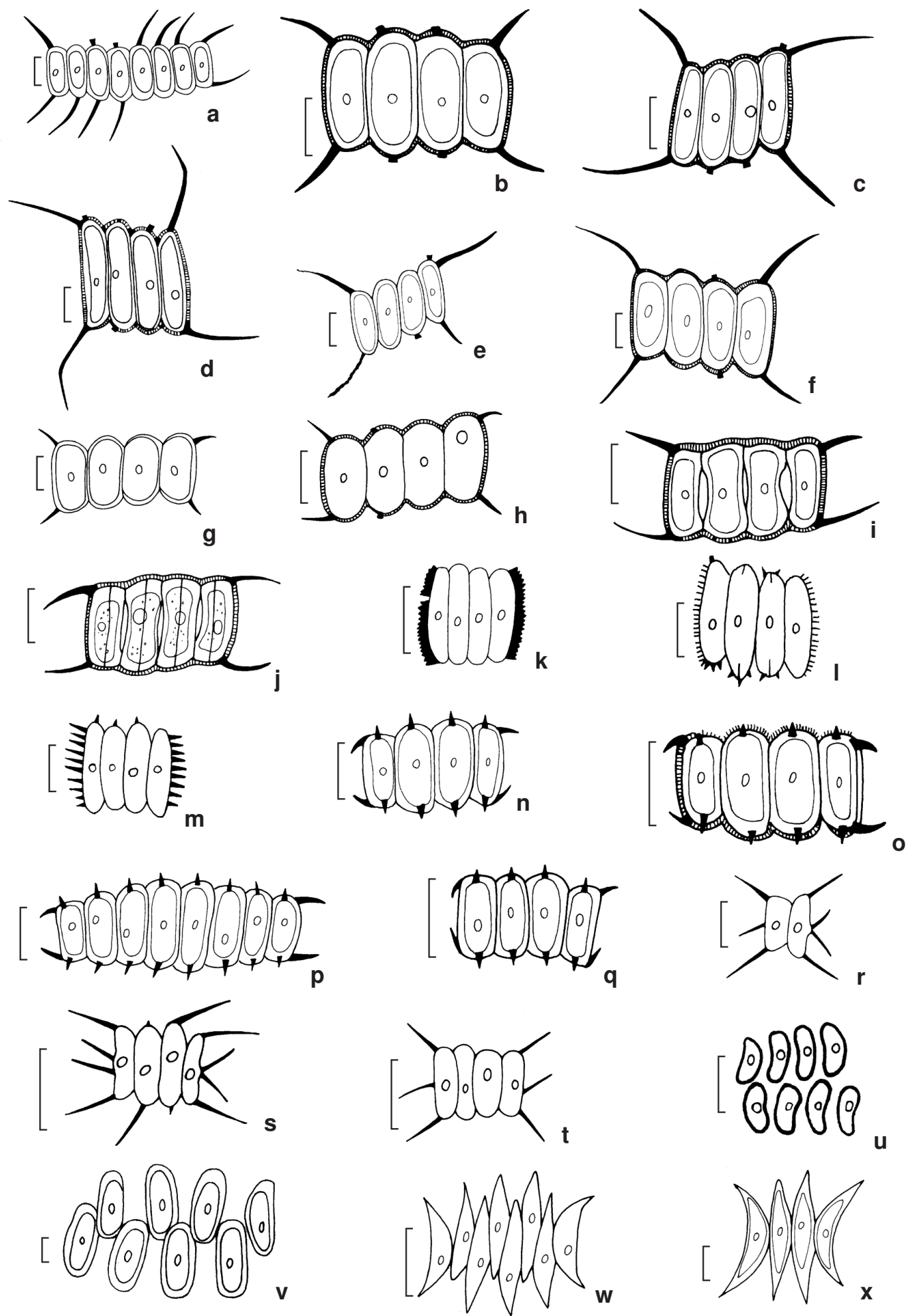

Figura 7 - a-f. Desmodesmus maximus. g-h. D. microspina. i-j. D. perforatus. k-m. D. serratus. n-q. D. spinoso-

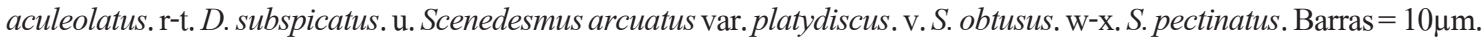
Figure 7 - a-f. Desmodesmus maximus. g-h. D. microspina. i-j. D. perforatus. k-m. D. serratus. n-q. D. spinoso-aculeolatus. r-t. D. subspicatus. u. Scenedesmus arcuatus var. platydiscus. v. S. obtusus. w-x. S. pectinatus. Bars $=10 \mu \mathrm{m}$. 

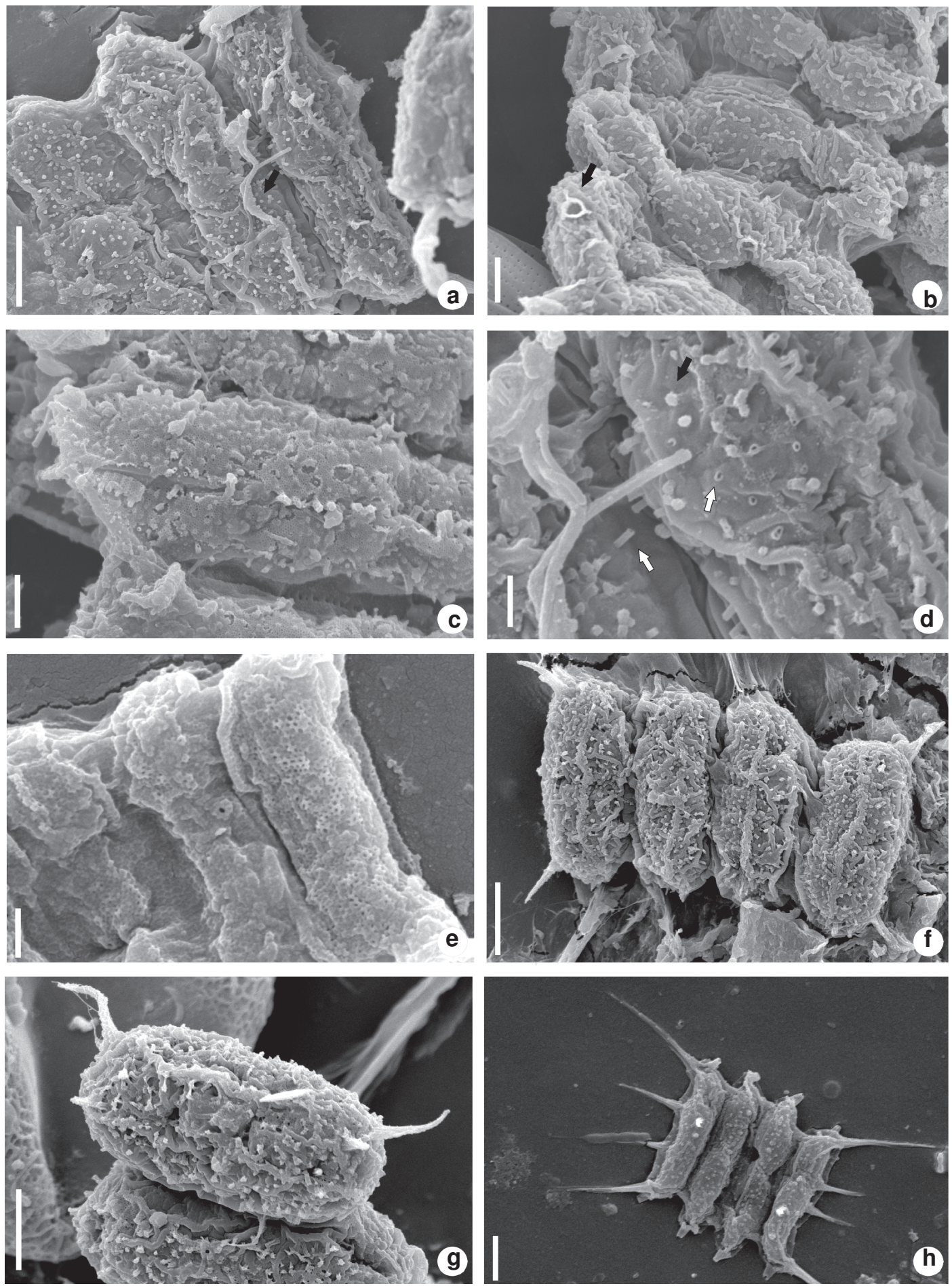

Figura 8 - a-e. Desmodesmus maximus - a. parede celular; b-d. detalhe da parede celular com roseta (seta preta) e com microtúbulos (setas brancas); e. parede celular apresentando ornamentações reticuladas. f-g. D. microspina. h. Vista geral de D. subspicatus, demonstrando costela frontal e verrugas na parede celular. Barras $=1 \mu \mathrm{m}(\mathrm{d}, \mathrm{e}) ; 2 \mu \mathrm{m}(\mathrm{b}, \mathrm{c}$, h); $5 \mu \mathrm{m}(\mathrm{a}, \mathrm{f}, \mathrm{g})$.

Figure 8 - a-e. Desmodesmus maximus - a. cell wall; b-d. detail of cell wall with rosette (black arrow) and microtubules (white arrows); e. cell wall showing reticulated ornamentations. f-g. D. microspina. h. General view of $D$. subspicatus, showing frontal rib and warts on cell wall. Bars $=1 \mu \mathrm{m}(\mathrm{d}, \mathrm{e}) ; 2 \mu \mathrm{m}(\mathrm{b}, \mathrm{c}, \mathrm{h}) ; 5 \mu \mathrm{m}(\mathrm{a}, \mathrm{f}, \mathrm{g})$. 

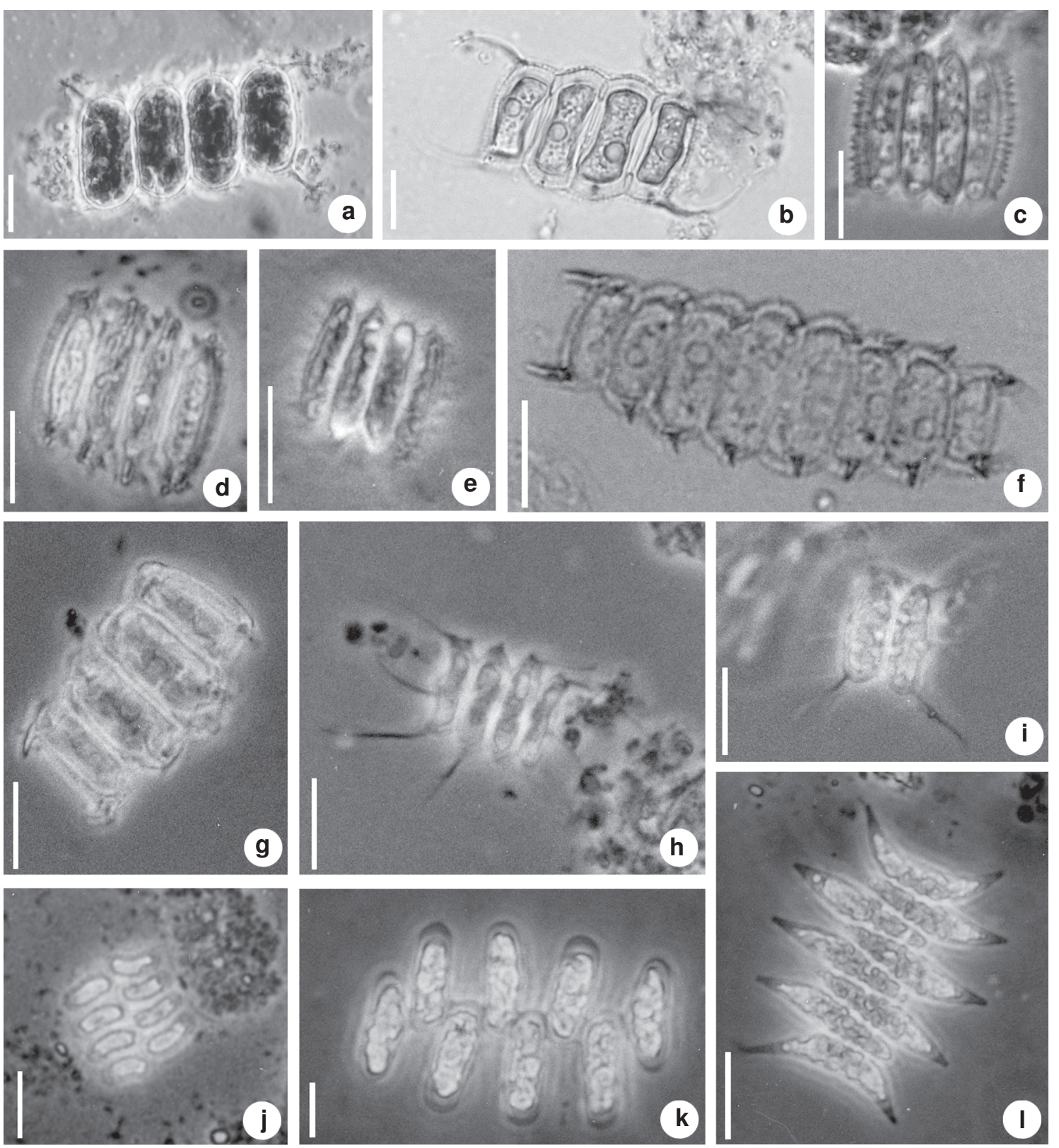

Figura 9 - a. Desmodesmus microspina. b. D. perforatus. c-e. D. serratus. f-g. D. spinoso-aculeolatus. h-i. D. subspicatus. j. Scenedesmus arcuatus var. platydiscus. k. S. obtusus. 1. S. pectinatus. Barras $=10 \mu \mathrm{m}$.

Figure 9 - a. Desmodesmus microspina. b. D. perforatus. c-e. D. serratus. f-g. D. spinoso-aculeolatus. h-i. D. subspicatus. j. Scenedesmus arcuatus var. platydiscus. k. S. obtusus. 1. S. pectinatus. Bars $=10 \mu \mathrm{m}$.

A presença de ornamentações na parede celular permite a transferência da espécie para o gênero Desmodesmus (An et al. 1999). Esta é a primeira citação da espécie para o estado do Rio Grande do Sul.

Material examinado: HAS 104231, 104358, 104446, 104447.
Desmodesmus subspicatus (Chod.) Hegew. \& Schimdt, Algol. Stud. 96: 17. $2000 . \quad$ Fig. 7r-t, 8h, 9h-i Cenóbios planos, com duas ou quatro células dispostas linearmente. Células oblongas, às vezes, com protuberância na região mediana das células externas. Presença frequente de espinho secundário nas células internas e de um 
ou dois espinhos laterais nas externas. Espinhos principais em disposição linear. Cloroplasto único, parietal, um pirenóide. Comprimento das células 6-12 $\mu \mathrm{m}, 2,8-4 \mu \mathrm{m}$, comprimento dos espinhos 5,5-12 $\mu \mathrm{m}$.

Ao microscópio eletrônico de varredura (MEV), foi possível observar verrugas e costela frontal em um indivíduo. Esta é a primeira citação da espécie para o estado do Rio Grande do Sul.

Material examinado: HAS 104097, 104104, 104349, 104384, 104446, 104447.

Scenedesmus arcuatus var. platydiscus G. M. Smith, Trans. Wisc. Acad. Sci. Arts \& Lett. 18:451, pl. XXX, fig. 101-105. 1916.

Fig. $7 \mathrm{u}, 9$ j

Cenóbios planos, com oito células dispostas linearmente em duas fileiras. Células reniformes, frouxamente unidas. Cloroplasto único, parietal, um pirenóide. Comprimento das células 7-10 $\mu \mathrm{m}$, largura 2-3 $\mu \mathrm{m}$.

Material examinado: HAS 104120, 104123.

Scenedesmus obtusus Meyen, Verh. K. Leopold.Carol. Akad. Naturf. 14: 775, pl. XLIII, figs. 30,31. 1829.

Fig. 7v, 9k

Cenóbios planos, com oito células dispostas alternadamente. Células oblongas, unidas lateralmente por uma pequena porção junto aos pólos. Espaços intercelulares conspícuos. Cloroplasto único, parietal, um pirenóide. Comprimento das células 20-26 $\mu \mathrm{m}$, largura 4,5-6 $\mu \mathrm{m}$.

Material examinado: HAS 104119, 104221, 104363.

Scenedesmus pectinatus Meyen, Verh. K. Leopold.Carol. Akad. Naturf. 14: 775, pl. XLII, figs. 33-35. 1829.

Fig. 7w-x, 91

Cenóbios planos, com quatro ou oito células dispostas linear ou alternadamente. Células fusiformes; internas quase retas, externas curvadas. Cloroplasto único, parietal, um pirenóide. Comprimento das células 12-33 $\mu \mathrm{m}$, largura 3-6 $\mu \mathrm{m}$.

A espécie é frequentemente confundida com S. acuminatus (Lagerh.) Chod., entretanto esta apresenta cenóbios curvos com prolongamentos nos pólos das células (Hegewald 1989; Nogueira 1991). Esta é a primeira citação da espécie para o estado do Rio Grande do Sul.

Material examinado: HAS 104101, 104104, 104119, 104120, 104122, 104123, HAS 104169, 104177, 104196, 104231, 104238, 104346, 104349, 104354, 104358, 104429, $104442,104447$.
Riqueza e densidade de Desmodesmus e Scenedesmus

A riqueza de Desmodesmus e Scenedesmus, na área da Lagoa do Casamento, no outono de 2003 (período de águas altas), variou de três espécies encontradas nas zonas litorânea e pelágica da Lagoa dos Gateados, a 12 espécies observadas na zona litorânea da lagoa do Casamento (Tab. 2). A temperatura da água variou entre $15,9^{\circ} \mathrm{C}$ (lagoa do Casamento) e $24,4^{\circ} \mathrm{C}$ (banhado entre L. Capivari e L. do Casamento) e o pH entre 6,2 (Canal do Sangradouro) e 8,8 (lagoa do Casamento). Na área do Butiazal de Tapes, a riqueza variou de uma espécie observada na Lagoa das Capivaras, na zona litorânea, a onze espécies no banhado com Sphagnum L. A temperatura oscilou entre $16,0{ }^{\circ} \mathrm{C}$ (Lagoa das Capivaras) e $21^{\circ} \mathrm{C}$ (banhado com Sphagnum) e o pH entre 6,4 (banhado com Sphagnum) e 6,7 (demais ambientes).

Na primavera de 2003, considerando-se as duas áreas de estudo, a riqueza variou entre duas espécies observadas na zona litorânea da lagoa Redonda a nove espécies, no banhado com Sphagnum (Tab. 2). Os valores de $\mathrm{pH}$ apresentaram pouca variação $(6,5-6,9)$, com exceção do banhado com Sphagnum, onde foi registrado pH de 4,3. A temperatura variou entre 22,3 e $32,4^{\circ} \mathrm{C}$, com o menor valor observado na lagoa Capivari e o maior no banhado com Sphagnum.

A densidade estimada de Desmodesmus e Scenedesmus (Tab. 2), considerando-se as duas estações e áreas de estudo, esteve correlacionada negativamente com $\mathrm{pH}(\mathrm{r}=-0,48 \mathrm{e} \mathrm{p}<0,02)$ (Fig. 10). No outono, na área da Lagoa do Casamento, a densidade variou entre 5 ind. $\mathrm{mL}^{-1}$ (lagoa Capivari) a 417 ind. $\mathrm{mL}^{-1}$ (Banhado Fazenda Rincão do Anastácio). Na área do Butiazal de Tapes, a densidade variou entre 3 ind. $\mathrm{mL}^{-1}$. (lagoa entre Dunas) a 798 ind. $\mathrm{mL}^{-1}$ (banhado com Sphagnum). Na primavera, considerando-se as duas áreas, a densidade variou entre um mínimo de 20 ind. $\mathrm{mL}^{-1}$, registrado na lagoa Capivari a um máximo de 8.813 ind. $\mathrm{mL}^{-1}$ no banhado com Sphagnum, habitat onde o $\mathrm{pH}$ atingiu o valor mais baixo $(\mathrm{ph}=0,43)$ (Tab. 2).

Comparando-se as estações de outono e primavera (Fig. 11), observa-se que a média de densidade (ind. $\mathrm{mL}^{-1}$ ) de Desmodesmus e Scenedesmus na primavera difere significativamente da média 
Tabela 2 - Variação da densidade e riqueza de Desmodesmus e Scenedesmus e do pH e temperatura da água, nos ambientes das áreas da Lagoa do Casamento (LC) e do Butiazal de Tapes (BT), no outono e primavera de 2003.

Table 2 - Density and richness variation of Desmodesmus and Scenedesmus and the variation of $\mathrm{pH}$ and water temperature, in the environments of Lagoa do Casamento (LC) and Butiazal de Tapes (BT) areas, in autumn and spring 2003.

\begin{tabular}{|c|c|c|c|c|c|c|c|}
\hline Estação & Área & Ambiente & Localização & $\begin{array}{l}\text { Densidade } \\
\left(\text { Ind. } \text { ml }^{-1} \text { ) }\right.\end{array}$ & Riqueza & pH & Temp. $\left({ }^{0} \mathrm{C}\right)$ \\
\hline \multirow[t]{17}{*}{ Outono } & $\mathrm{LC}$ & B. L. Cap. e L. Cas. & Litoral & 266 & 7 & 6,6 & 24,4 \\
\hline & $\mathrm{LC}$ & L. Capivari & Pelágica & 5 & 5 & 6,7 & 20,6 \\
\hline & $\mathrm{LC}$ & L. Casamento & Litoral & 27 & 12 & 8,8 & 15,9 \\
\hline & $\mathrm{LC}$ & L. Casamento & Pelágica & 53 & 5 & 7,6 & 20,4 \\
\hline & $\mathrm{LC}$ & B. Faz. Rincão & Litoral & 417 & 11 & 6,4 & 18,0 \\
\hline & $\mathrm{LC}$ & B. Faz. Rincão & Pelágica & 56 & 6 & 6,4 & 18,0 \\
\hline & $\mathrm{LC}$ & L. Gateados & Litoral & 15 & 3 & 6,5 & 16,9 \\
\hline & $\mathrm{LC}$ & L. Gateados & Pelágica & 13 & 3 & 6,8 & 17,2 \\
\hline & $\mathrm{LC}$ & C. Sangradouro & Litoral & 59 & 10 & 6,2 & 16,2 \\
\hline & BT & L. Charutão & Litoral & 82 & 5 & 6,5 & 16,9 \\
\hline & BT & L. Charutão & Pelágica & 47 & 3 & 6,5 & 16,9 \\
\hline & BT & L. Capivaras & Litoral & 4 & 1 & 6,7 & 16,0 \\
\hline & BT & L. Capivaras & Pelágica & 7 & 2 & 6,7 & 16,9 \\
\hline & BT & L. Dunas & Litoral & 3 & 2 & 6,7 & 17,0 \\
\hline & BT & B. Dunas & Litoral & 10 & 4 & 6,7 & 17,0 \\
\hline & BT & B. Sphagnum & Litoral & 798 & 11 & 6,4 & 21,0 \\
\hline & BT & L. Redonda & Litoral & 49 & 9 & 6,7 & 17,0 \\
\hline \multirow[t]{8}{*}{ Primavera } & $\mathrm{LC}$ & B.L. Cap. e L. Cas. & Litoral & 94 & 4 & 6,7 & 24,2 \\
\hline & $\mathrm{LC}$ & L. Capivari & Pelágica & 20 & 4 & 6,9 & 22,3 \\
\hline & $\mathrm{LC}$ & L. Casamento & Litoral & 152 & 6 & 6,7 & 24,4 \\
\hline & $\mathrm{LC}$ & L.Casamento & Pelágica & 100 & 4 & 6,9 & 22,4 \\
\hline & $\mathrm{LC}$ & L. Casamento & Litoral & 30 & 7 & 6,5 & 23,0 \\
\hline & $\mathrm{LC}$ & B. Faz. Rincão & Litoral & 72 & 5 & 6,6 & 27,1 \\
\hline & BT & B. Sphagnum & Litoral & 8813 & 9 & 4,3 & 32,4 \\
\hline & BT & L. Redonda & Litoral & 667 & 2 & 6,5 & 31,2 \\
\hline
\end{tabular}

obtida no outono $(\mathrm{p}=0,04)$. Na primavera, ocorreram as maiores densidades, o que pode ser explicado não só pelas maiores temperaturas, como também pelo menor nível das águas nesta estação, o que possibilita, provavelmente, maior concentração dos organismos. A temperatura da água parece exercer um papel importante no desenvolvimento das Chlorococcales como já mencionado por Philipose (1967). Observa-se que, tanto no outono quanto na primavera, os picos de densidade estiveram acompanhados pelos de temperatura da água.
Comparando-se a riqueza encontrada nas zonas litorânea e pelágica (Fig. 12) das lagoas e dos banhados, constatou-se que a média da riqueza na zona litorânea difere significativamente da média obtida na zona pelágica $(\mathrm{p}=0,02)$, sendo maior na zona litorânea, devido, provavelmente, à presença de macrófitas, que acabam mantendo as algas nas margens, no metafíton. Além disso, temse conhecimento de que as Scenedesmaceae toleram longos períodos sem luz, sendo boas competidoras nesse tipo de ambiente (Lürling \& Van Donk 2000). 


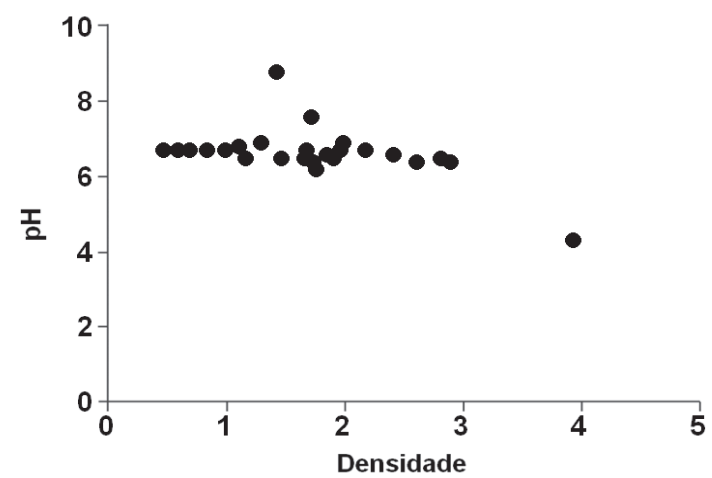

Figura 10 - Variação da densidade (log) de Desmodesmus e Scenedesmus em relação ao $\mathrm{pH}$, nas áreas da Lagoa do Casamento e do Butiazal de Tapes no outono e primavera de 2003.

Figure 10 - Density variation ( $\log$ ) of Desmodesmus and Scenedesmus and their relation with the $\mathrm{pH}$, in Lagoa do Casamento and Butiazal de Tapes areas, in autumn and spring 2003.

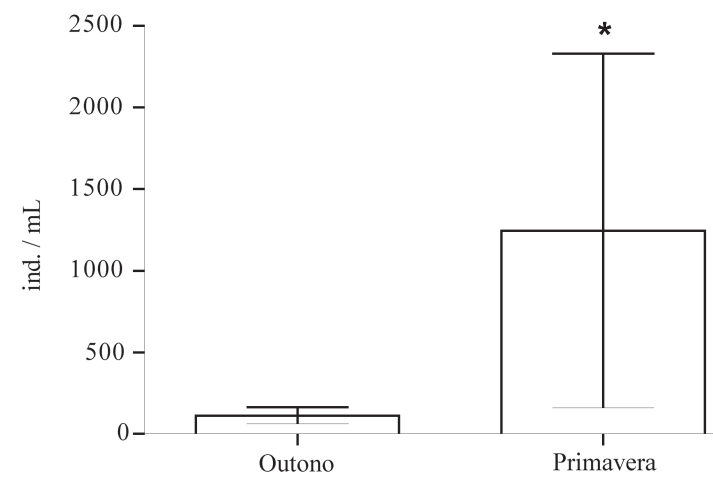

Figura 11 - Densidade de Desmodesmus e Scenedesmus, em relação às estações de outono (águas altas) e primavera (águas baixas) de 2003, nas áreas da Lagoa do Casamento e do Butiazal de Tapes.

Figure 11 - Desmodesmus and Scenedesmus density and their relation with the seasonal changes during autumn (high waters) and spring (low waters) 2003, in Lagoa do Casamento and Butiazal de Tapes areas.

É interessante observar que Desmodesmus e Scenedesmus são de comum ocorrência em ambientes com pH neutro ou levemente básico (Philipose 1967). Entretanto, nas áreas estudadas, esses gêneros apresentaram maiores valores de riqueza e densidade no banhado com Sphagnum, onde o $\mathrm{pH}$ foi mais baixo $(\mathrm{pH}=4,3)$. Desmodesmus komarekii, D. maximus, D. microspina e D. brasiliensis foram as espécies abundantes, demonstrando tolerância a esta condição.

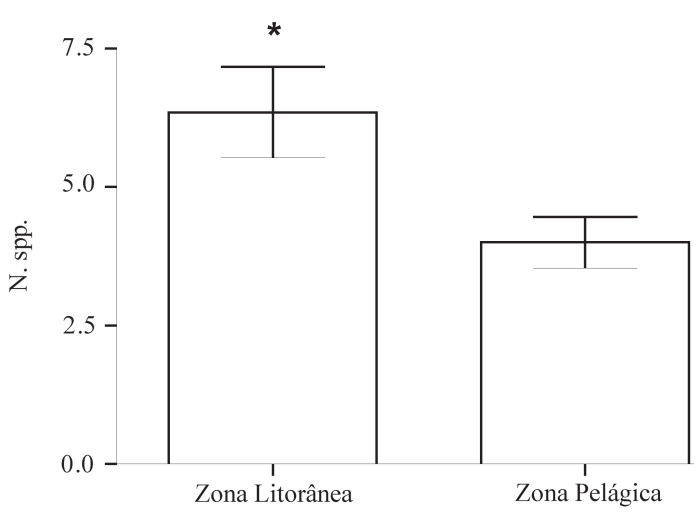

Figura 12 - Riqueza de Desmodesmus e Scenedesmus, em relação às zonas litorâneas e pelágicas dos ambientes amostrados, no outono (águas altas) e primavera (águas baixas) de 2003 .

Figure 12 - Desmodesmus and Scenedesmus richness and their relation with litoral and pelagic zones of the sampled environments, in autumn (high waters) and spring (low waters) 2003.

\section{Agradecimentos}

Os autores agradecem à Coordenação de Aperfeiçoamento de Pessoal de Nível Superior e ao Conselho Nacional de Desenvolvimento Científico e Tecnológico as Bolsas de Mestrado e de Produtividade em Pesquisa, concedidas ao primeiro e segundo autor, respectivamente. Aos pesquisadores do Centro de Geoprocessamento do Museu de Ciências Naturais, Fundação Zoobotânica do Rio Grande do Sul e aos técnicos Centro de Microscopia Eletrônica da Universidade Federal do Rio Grande do Sul, pelo apoio técnico prestado.

\section{Referências}

An, S.S.; Friedl, T. \& Hegewald, E. 1999. Phylogenetic relationships of Scenedesmus and Scenedemus-like coccoid green algae as infered from ITS-2 rDNA sequence comparisons. Plant Biology 1: 418-428.

Bicudo, C.E.M. \& Menezes, M. 2005. Gêneros de algas de águas continentais do Brasil (chave para identificação e descrições). Rima, São Carlos, São Paulo.

Fortes, D.F.; Torgan, L.C. \& Júnior, A.S. 2003. Composição e variação sazonal do fitoplâncton (ClorophytaChlorococcales s.l) próximo à foz do Rio dos Sinos, em uma área pertencente ao Parque Estadual Delta do Jacuí, RS, Basil. Iheringia, Série Botânica 52: 103-129.

Garcia, M. \& Vélez, E. 1995. Algas planctônicas da lagoa Emboaba, Planície Costeira do Rio Grande do Sul: Avaliação qualitativa. Boletim do Instituto de Biociências 54: 75-114. 
Hegewald E. 1978. Eine neue unterleitung der gattung Scenedesmus Meyen. Nova Hedwigia 30: 343-376.

Hegewald, E. 1989. The Scenedesmus strains of the culture collection of the University of Texas at Austin (UTEX). Algological Studies 55: 153-189.

Hegewald, E. 2000. New combinations in the genus Desmodesmus (Chlorophyceae, Scenedesmaceae). Algological Studies 96: 1-18.

Hegewald, E. \& Krienitz, L. 1993. Studies on Scenedesmus costato-granulatus var. elegans (Hortob.) Hegewald et Krienitz comb. Et stat. nov. Algological Studies 70: $1-10$.

Hegewald, E.; Schmidt, A. \& Schnepf, E. 2001. Revision der lateral bestachelten Desmodesmus-Arten. 1.Desmodesmus subspicatus (R. Chod.) E. Hegew. Et A. Schmidt. Algological Studies 101: 1-26.

Hegewald, E. \& Silva, P. C. 1988. Annotated catalogue of Scenedesmus and nomenclaturally related genera, including original descriptions and figures. Bibliotheca Phycologica 80. J. Cramer, Stuttgart. 587p.

Hegewald, E. \& Wolf, M. 2003. Phylogenetic relationships of Scenedesmus and Acutodesmus (Chlorophyta, Chlorophyceae) as infered from 18S rDNA and ITS2 sequence comparisons. Plant Systematics and Evolution 241: 185-191.

Hindàk, F. 1990. Studies on the Chlorococcal algae (Chlorophyceae) V. Slovak Academy of Sciences, Bratislava. 225p.

Komàrek, J. \& Fott, B. 1983. Chlorophyceae-Chlorococcales In: Huber-Pestalozzi, G. Das Phytoplankton des Süsswassers. Systematik und Biologie Pt 7. E. Schweizerbart'sche Verlagsbuchhandlung, Stuttgart. 1044p.

Lewis, L.A. \& McCourt, R.M. 2004. Green algae and the origin of land plants. American Journal of Botany 9: 1535-1556.

Lürling, M. \& Van Donk, E. 2000. Grazer-induced colony formation in Scenedesmus: are there costs to being colonial? (Chemichal communication in Aquatic Systems). Oikos 88: 111-118.

Meyen F.J.F. 1829. Beobachtungen über einiege niedere Algenformen. Verhandlungen der Kaiserlichen Leopokdinisch-Carolinischen Akademie der Naturforscer 14: 769-778.

Nogueira, I.S. 1991. Chlorococcales sensu lato(Chlorophyceae) do município de Rio de Janeiro e arredores, Brasil: inventário e considerações taxonômicas. Dissertação de Mestrado. Universidade Federal do Rio de Janeiro, Rio de Janeiro. 356p.

Pappas, J.L. \& Stoermer, E.F. 1996. Quantitative method for determining a representative algal sample count. Journal of Phycology 32: 693-696.

Philipose, M.T. 1967. Chlorococcales. Indian Council of Agricutural Research, Nova Delhi. 365p.

Rosa, Z.M. \& Oliveira, M.B. 1990. Chlorococcales (Chlorophyceae) de corpos d'água do Município de São Jerônimo, Rio Grande do Sul, Brasil. Iheringia, Série Botânica, Porto Alegre 40: 89-114.

Torgan, L.C.; Barreda, K.A. \& Fortes, D.F. 2001. Catálogo das algas Chlorophyta de águas continentais e marinhas do estado do Rio Grande do Sul, Brasil. Iheringia Série Botânica 56: 147-182.

Torgan, L.C.; Alves, S.M.; Werner, V.R.; Rosa, Z.M.; Cardoso, L.S.; Rodrigues, S.C.; Santos, C.B.; Palma, C.; Fortuna, J.; Bicca, A.B. \& Weber, A.S. Ficoflora. In: Becker, F.G.; Ramos, R.A. \& Moura L.A. (org.). 2007. Biodiversidade. Regiões da Lagoa do Casamento e dos Butiazais de Tapes, Planície Costeira do Rio Grande do Sul. Ministério do Meio Ambiente, Brasília. Pp. 112-127.

Tsarenko, P.M. \& Petlevanny O.A. 2001 Doplolneniek "Raznoobraziju vodoroslej Ukrainy". Algologia, Suppl. Pp. 1-130.

Utermöhl, H. 1958. Zur Vervollkommnung der quantitativen Phytoplankton Methodik. Mitt. int. Vereinigung fur Theoretische und Angewandte Limnologie 9: 1-38. 